
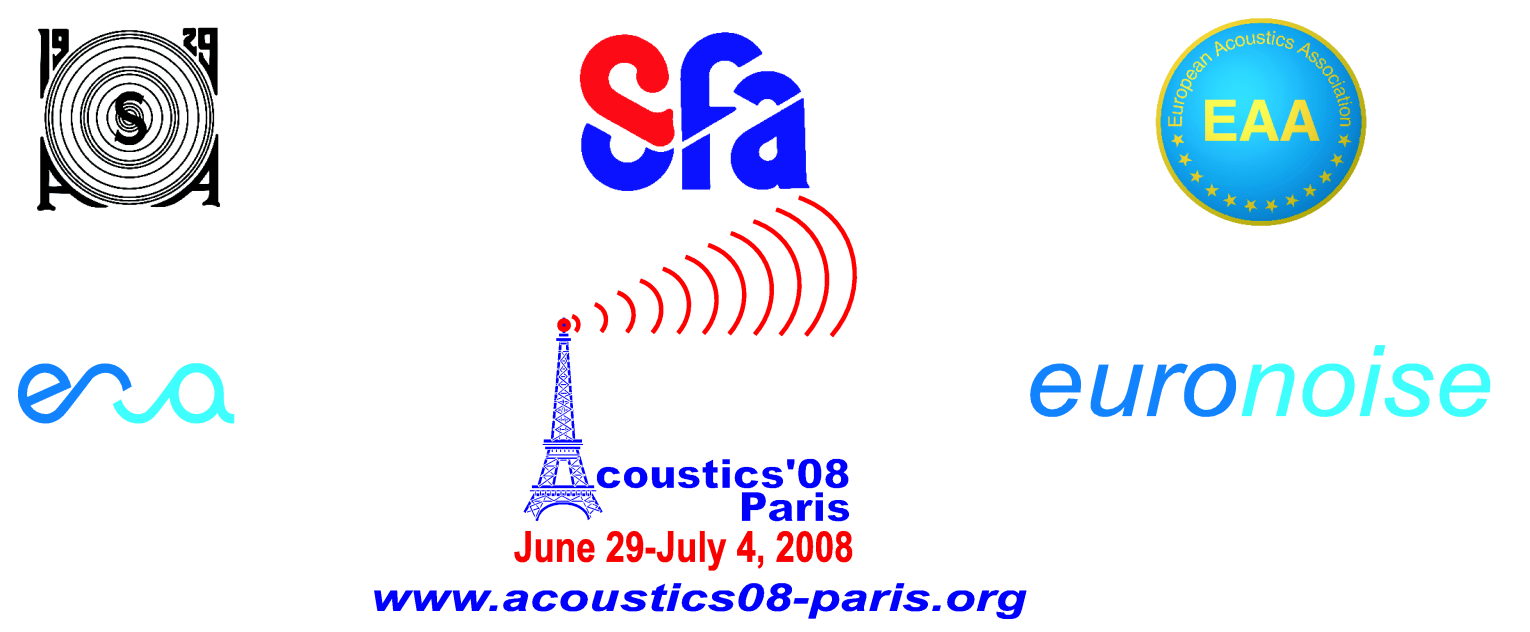

\title{
Ultrasonic pulse propagation in a bonded three-layered structure
}

J.L. San Emeterio ${ }^{a}$, A. Ramos ${ }^{\mathrm{a}}$, E. Pardo ${ }^{\mathrm{a}}$, J. C B Leite ${ }^{\mathrm{b}}$, J. Miguel Alvarez ${ }^{\mathrm{c}}$ and C. Perez Trigo ${ }^{\mathrm{c}}$

anstituto de Acustica CSIC, Serrano 144, 28006 Madrid, Spain ${ }^{\mathrm{b}}$ COPPE, Universidad Federal Rio de Janeiro, 68501 Rio de Janeiro, Brazil

'INTA, Carretera Ajalvir, Km 4, 28850 Madrid, Spain

jluis@ia.cetef.csic.es 
Bonded layers are used in the assembly of many critical functional parts of industrial equipment. In this work, ultrasonic pulse propagation in a steel-rubber-rubber bonded composite structure is investigated by means of computer simulation and pulse echo experimental evaluation. Ultrasonic pulse propagation is modelled using a 2D time domain finite-difference software. For the experimental measurements, two test samples were fabricated by bonding a thin layer of steel and two thin layers of rubber, including debonded areas at marked regions of each interface. Several ultrasonic traces were acquired by contact pulse-echo testing, using a $5 \mathrm{MHz}$ wideband transducer, from the external steel surface. The large acoustic impedance mismatch existing between steel and rubber layers makes that only a very small part of the ultrasonic energy is transmitted through the first interface. The high attenuation in rubber materials and the possible overlapping of multiple echoes due to the small thickness of the different layers are additional characteristics of the ultrasonic pulse propagation in this flat structure. Some differences in time and frequency domains, between the received signals from normal bonded areas and completely debonded areas are discussed, looking for defect detection at the first (steel-rubber) and second (rubber-rubber) interfaces.

\section{Introduction}

Different Nondestructive Testing (NDT) techniques can be used to ensure the quality of bonded structural components and their interfaces. Mechanical impedance analysis, shearography, termography, optical holography, ultrasonics and other sonic and vibration techniques are among these NDT techniques. Ultrasonic methods, which are already widely used, include compression and shear wave techniques as well as methods based on Lamb waves. Ultrasonic wave propagation in multilayered structures has been well described elsewhere [1-3].

In this paper, ultrasonic pulse-echo techniques are used to investigate the interface regions of a bonded three layer (steel-rubber-rubber) flat structure. Computer simulated and experimental ultrasonic traces are used to analyse received signals from normal bonded areas and completely debonded areas, looking for defect detection at the first (steel-rubber) and second (rubber-rubber) interfaces.

A pulse-echo contact method, from the outside metallic surface, with a longitudinal normal beam transducer, is used for studying the bond integrity of the interfaces, in accordance with practical situations where throughtransmission techniques can not be applied. Difficulties for such type of ultrasonic inspection derive from several points: a) the large acoustic impedance mismatch existing between steel and rubber layers, causing that only a very small part of the ultrasonic energy is transmitted through the first interface; b) The high attenuation in rubber materials; c) Multiple reflections on the steel layer and overlapping of multiple echoes due to its small thickness. Specific signal processing techniques usually play a notable role in detection and characterization of adherence conditions [4-7]. Wavelet processing has been recently used to separate superimposing echoes as well as for noise reduction and signal detection for ultrasonic NDT [8-11].

In this paper, the complex ultrasonic pulse propagation in a steel-rubber-rubber three-layer structure is first investigated by means of computer simulation using both an approximate 1D model and a 2D time domain finite difference software (Wave2000, Cyberlogic). Some experimental measurements at $5 \mathrm{MHz}$ are further presented and, finally, detection of debonding at the interfaces (particularly the extremely difficult detection of debonding at the second rubber-rubber one [12]) is commented.

\section{Modelling Ultrasonic Pulse Propagation in the layered structure}

A test sample of lateral dimensions $300 \mathrm{~mm}$ x $200 \mathrm{~mm}$ was fabricated by bonding a thin layer $(2 \mathrm{~mm})$ of steel and two thin layers of an EPDM rubber $(2.7 \mathrm{~mm}$ in thickness each one). Debonded areas at marked regions of each interface were introduced. These artificial defects have lateral dimensions of $40 \mathrm{~mm} \times 40 \mathrm{~mm}$. Figure 1 shows a C-scan image of the sample where 6 debonded areas can be appreciated. Single layer samples of the involved materials, with different thickness, were separately tested to assess some acoustic properties of those materials. Densities $\rho$ were measured by differential weighting in air and water immersion. Longitudinal wave velocities $\mathrm{V}_{\mathrm{L}}$, in both steel and rubber, were measured at $5 \mathrm{MHz}$ by direct contact measurements of thickness and time-of-flight. Longitudinal wave attenuations, in both steel and rubber, were estimated at $5 \mathrm{MHz}$ by direct measurement in pulse-echo immersion technique. These measurements are summarized in Table I.

One-dimensional models of ultrasonic wave propagation in multi-layers are frequently used. Since the dimensions of defects are much larger than the thickness of the different layers and the probe diameter, a 1D model has been used as a first approach to compute time of arrival and signal amplitude of the successive echoes.

\begin{tabular}{|c|c|c|c|c|c|}
\hline Material & $\rho\left(\mathrm{Kg} / \mathrm{m}^{3}\right)$ & $\mathrm{V}_{\mathrm{L}}(\mathrm{m} / \mathrm{s})$ & $\left.\mathrm{V}_{T} \mathrm{~m} / \mathrm{s}\right)$ & $\left.\alpha_{\mathrm{L}} \mathrm{dB} / \mathrm{cm}\right)$ & $\left.\alpha_{T} \mathrm{~dB} / \mathrm{cm}\right)$ \\
\hline (1) Steel & 7830 & 5990 & 3800 & 1 & 3 \\
\hline$(2,3)$ Rubber & 1545 & 1695 & 406 & 90 & 1030 \\
\hline
\end{tabular}

Table I. Material properties of different layers at $5 \mathrm{MHz}$ 


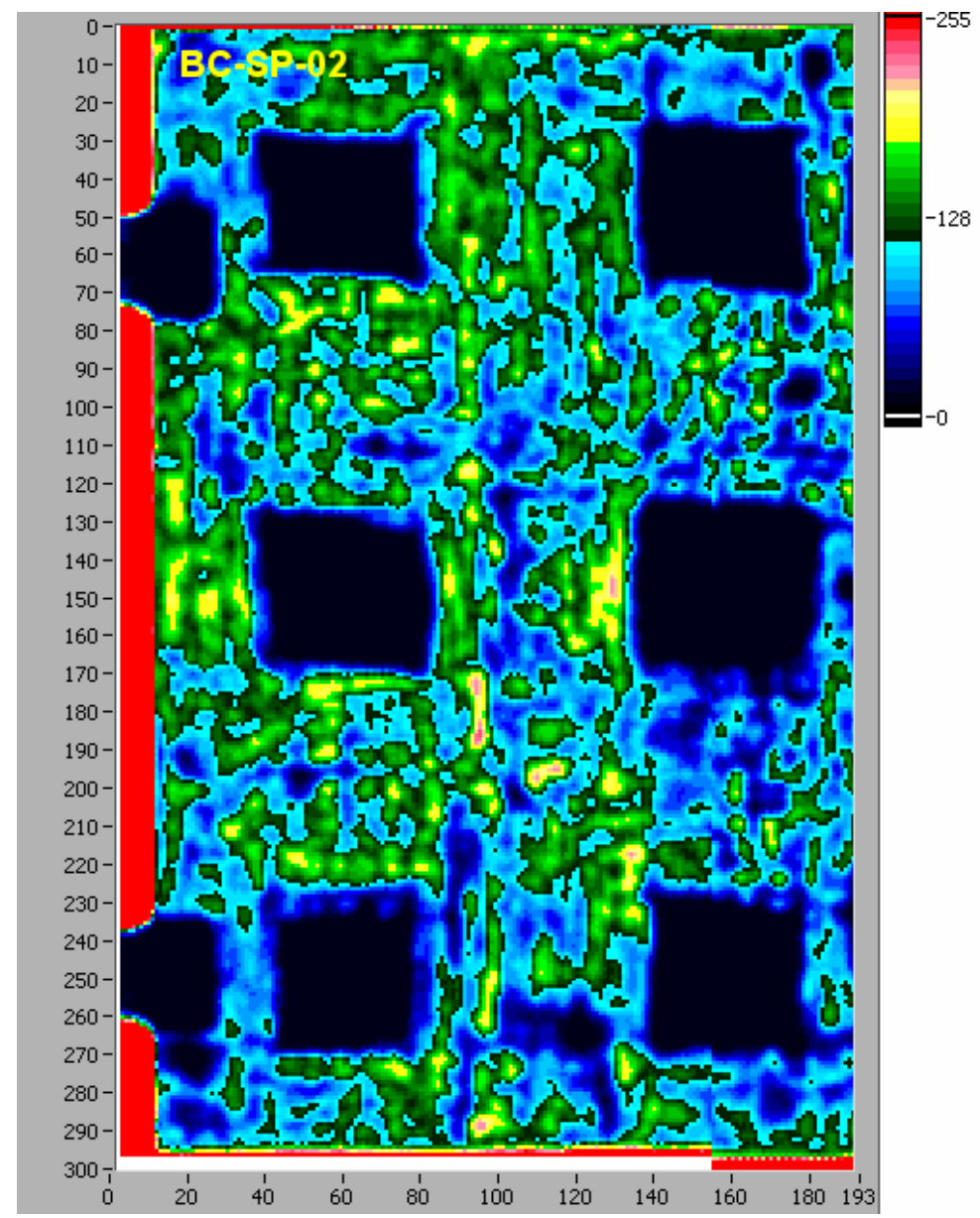

Figure 1. Ultrasonic C-scan of the three layer sample

Layers of homogeneous materials with perfect flat parallel boundaries are assumed. In a simple scheme of this three layer structure, layer (1) corresponds to steel and layers (2) and (3) to rubbers. In this first analysis, layers (2) and (3) are assumed to be of the same rubber material, so that only complete debond at the second rubber-rubber interface is modelled. Material properties of Table I will be used in the modelling of ultrasonic pulse propagation. Artificial defects corresponding to completely debonded areas are modelled by means of additional very thin air layers located at the corresponding interface [5,12]. Only longitudinal wave propagation is assumed in this first approach.

When a complete debonding is present at the first steelrubber interface, the time of arrival $\tau$ and amplitude A of the reverberant echo number $\mathrm{n}$ can be obtained from:

$$
\begin{aligned}
& \tau_{\text {steel }}(\mathrm{n})=2 \mathrm{nd}_{\text {steel }} / \mathrm{v}_{\text {Lsteel }} \\
& \mathrm{A}_{\text {steel }}(\mathrm{n})=\exp \left(-2 \mathrm{nd}_{\text {steel }} \alpha_{\text {Lsteel }}\right)
\end{aligned}
$$

where, $\mathrm{d}$ is the thickness, $\mathrm{v}_{\mathrm{L}}$ the longitudinal velocity, and $\alpha_{L}$ the attenuation coefficient of longitudinal waves. A unitary amplitude of the incident pulse and a perfect reflection at both interfaces (steel-air) are assumed.
When a complete debonding is present at the second rubber-rubber interface and there is no defect at the first interface, the times of arrival and amplitudes of the different echoes can be obtained from

$$
\begin{gathered}
\tau_{\text {rubber }}(\mathrm{n})=\mathrm{n}\left(\left(2 \mathrm{~d}_{\text {steel }} / \mathrm{v}_{\text {Lsteel }}\right)+\left(2 \mathrm{~d}_{\text {rubber }} / \mathrm{v}_{\text {Lrubber }}\right)\right) \\
\mathrm{A}_{\text {steel }}(\mathrm{n})=\exp \left(-2 \mathrm{n} \mathrm{d}_{\text {steel }} \alpha_{\text {Lsteel }}\right)\left(\mathrm{R}_{12}\right)^{\mathrm{n}} \\
\mathrm{A}_{\text {rubber }}(\mathrm{n})=\exp \left(-2 \mathrm{n} \mathrm{d}_{\text {steel }} \alpha_{\text {Lsteel }}\right) \exp \left(-2 \mathrm{n} \mathrm{d}_{\text {rubber }} \alpha_{\text {Lrubber }}\right)\left(\mathrm{T}_{12} \mathrm{~T}_{21}\right)^{\mathrm{n}}
\end{gathered}
$$


reverberant echoes in steel are also given by Eq. (1).

Figure 2 shows the amplitudes and arrival times of the reverberant echoes in the steel layer, computed for the cases of perfect bonding (o) and complete debonding (*) at the steel-rubber interface. The amplitude and time of arrival of the first echo from a debonding at the second rubber-rubber interface is also displayed $(+)$.

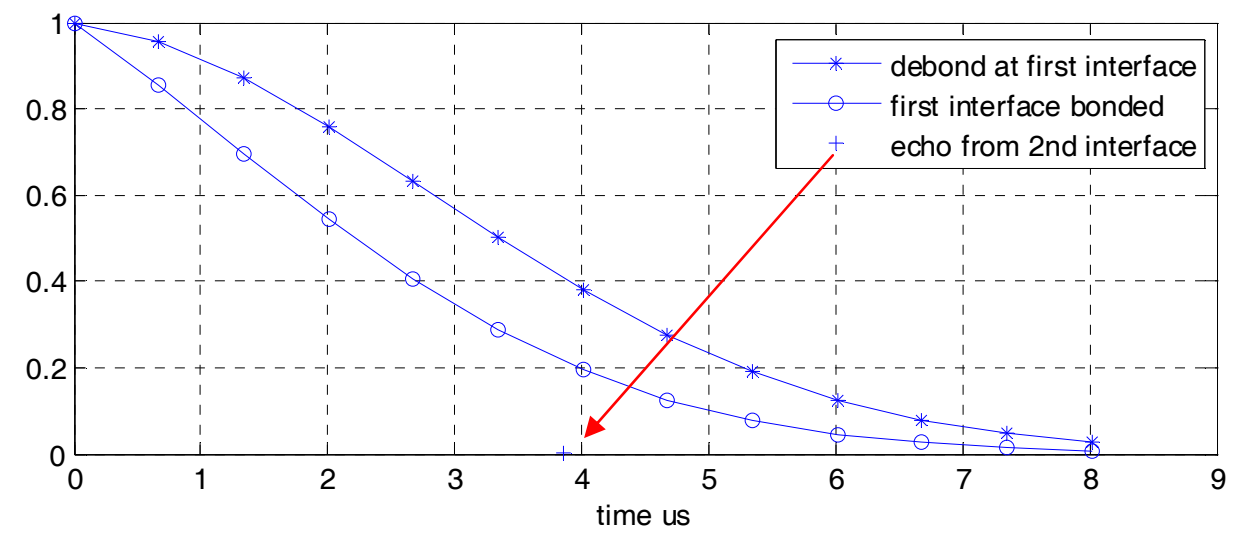

Figure 2. Amplitudes and times of arrival of reverberant echoes and echo from second interface

In addition, several 2D models of the three layer structure were developed using Wave2000 (Cyberlogic). A viscous model for material losses is adopted in the finite-difference time-domain (FDTD) method. Shear wave properties in rubber have been estimated from bibliographic data. Figure 3 shows a finite-difference model of the structure with a complete debonding in the second (rubber-rubber) interface, represented by an $0.1 \mathrm{~mm}$ air layer (aspect ratio has been modified in the figure). It also shows a snapshot of the ultrasonic pulse structure at time instant $t=4.094$ $\mu \mathrm{s}$, a short time after the first ultrasonic pulse has arrived from the second interface. The following characteristics have been assumed in the model: a piston type source of 5 $\mathrm{MHz}$ and $6 \mathrm{~mm}$ in diameter, located at the central position of the left external (steel) interface; the specific pulsed time waveform of the source is selected as a sinusoidal carrier wave with Gaussian envelope and very broad bandwidth; the transducer works in pulse-echo mode and infinite boundary conditions, absorbing all the incident pulses, are assumed at the upper and lower horizontal boundaries (Fig. 3); air is assumed as the medium after the right-most interface.

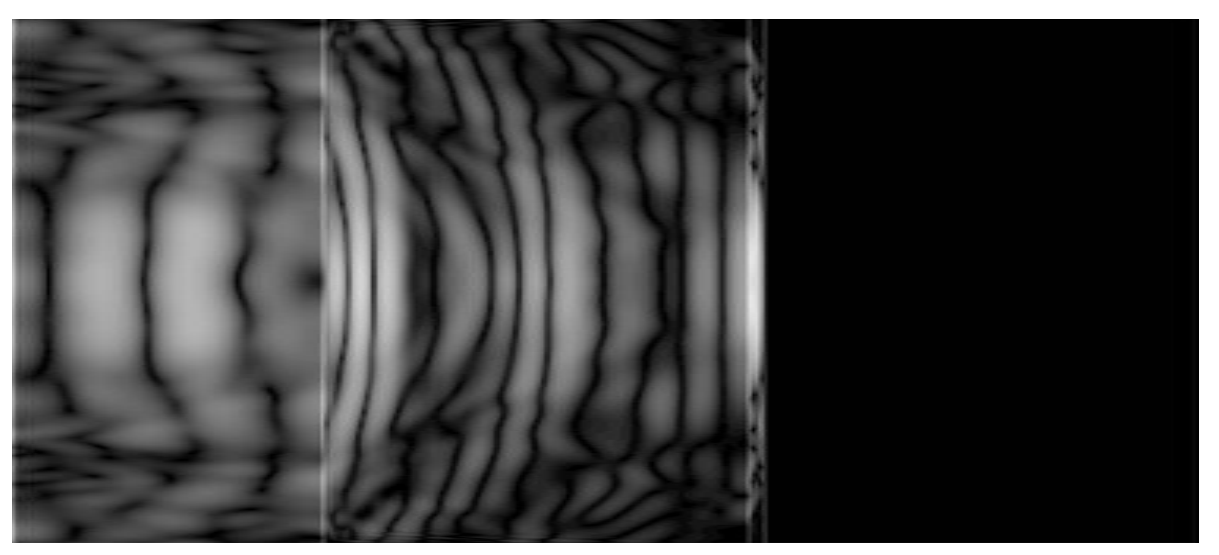

Figure 3. Finite difference simulation. Snapshot of the ultrasonic pulse propagation at time $t=4.094 \mu$ s.

Figure 4 shows the pulse-echo time domain waveforms simulated for three different models: a) with perfect bonding conditions at the two interfaces (steel-rubber) and (rubber-rubber); b) with total debonding in the first interface (air layer of $0.1 \mathrm{~mm}$ ); and c) with total debonding in the second interface (air layer of $0.1 \mathrm{~mm}$ ). The higher amplitude of the curves in the case of complete debonding at the first interface (b) can be easily appreciated, as it was apparent in figure 2 . 

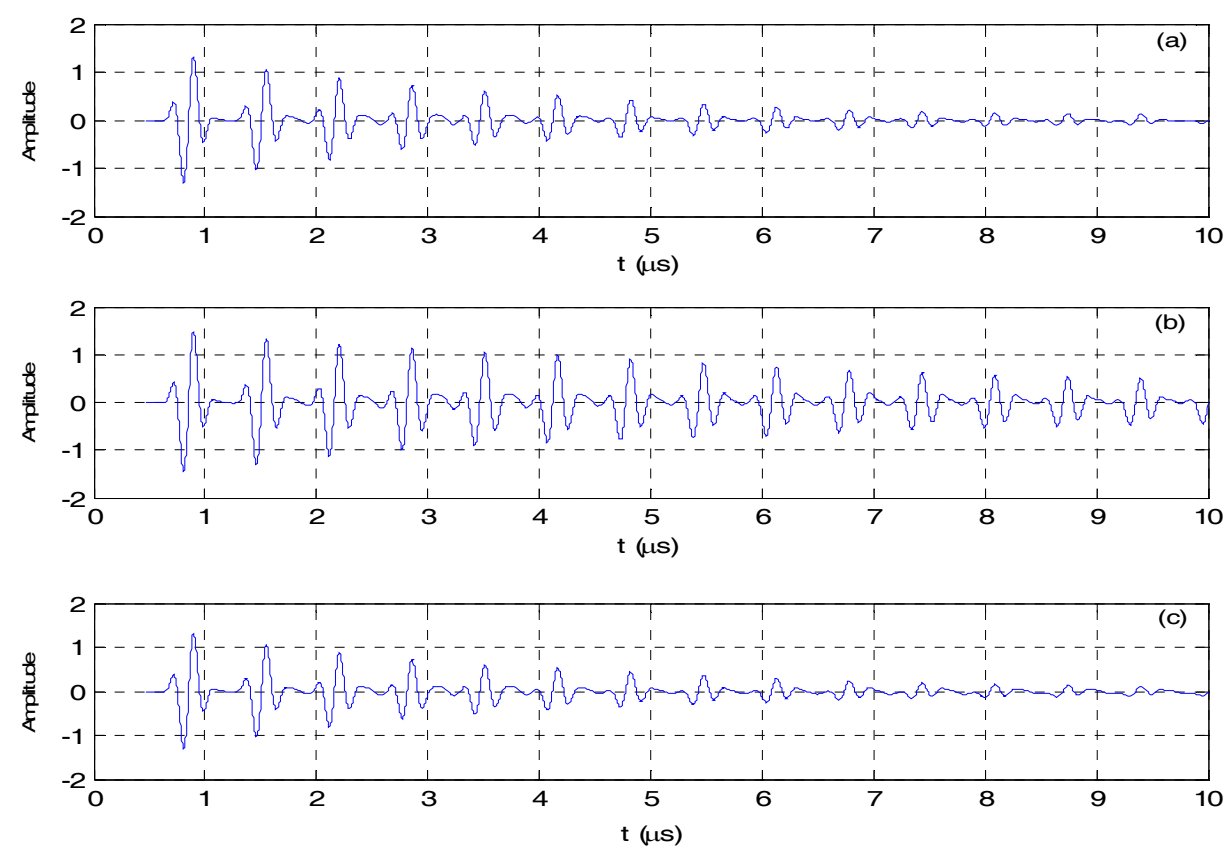

Figure 4. Pulse-echo waveforms. (a) perfect bonding conditions at both interfaces; (b) total debonding at the first, steel-rubber, interface; (c) total debonding at the second, rubber-rubber, interface

\section{Experimental measurements}

Several ultrasonic traces were acquired at different marked locations, corresponding to defect-free zones and also to zones with different types of defect, for two test samples. An Ultrasonic Analyzer (Panametrics 5052 UA), and an ultrasonic transducer (Panametrics $310 \mathrm{~S}$ ) of $5 \mathrm{MHz}$ central frequency and 0.25 " in diameter were used.

Figures 5.a and 6.a show the time domain waveforms in two different cases: i) with a complete debonding in the first (steel-rubber) interface, and ii) without defect in any interface, respectively. Figures $5 . b$ and $6 . b$ show the corresponding frequency spectrum of the previous traces.
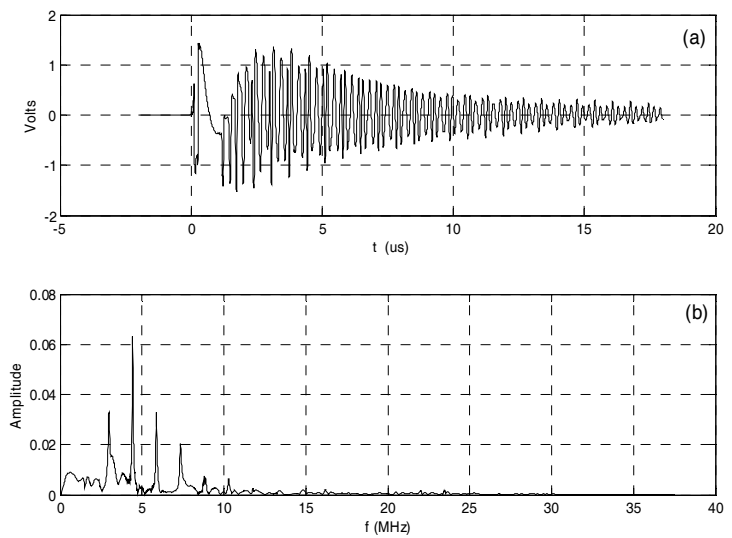

Figures 5. Experimental waveform acquired from a zone with a complete debond at the first interface.
The resonance spectrum, with peaks at 2.99, 4.44, 5.87, $7.35,8.81,10,29 \mathrm{MHz}$, corresponding to reverberations into the steel layer, can be noted. The change in the amplitude of both time domain signals and frequency spectra in the cases i) no defect, (Figure 3), and ii) complete debonding in the first interface (Figure 4), can be easily appreciated. Extremely small changes in the frequency peak amplitudes were observed between the cases of perfect bonding and complete debonding at the second interface (figure not included).
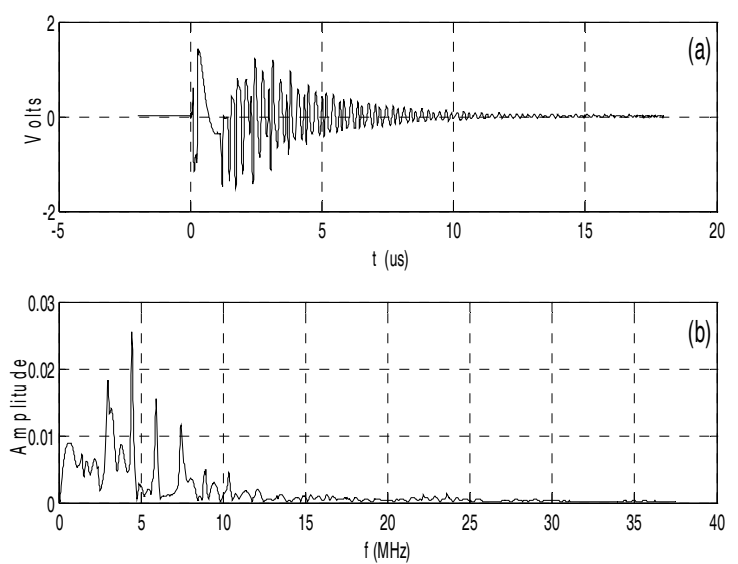

Figure 6. Experimental waveform acquired from a zone with a good bonding conditions. 


\section{Conclusion}

Steel-rubber-rubber multilayer structures are common in some aeronautical applications. Debonding at first steelrubber interface can be detected measuring the amplitude of the ultrasonic reflected echoes. Defect detection at the second rubber-rubber interface is an open problem of great interest. Models can be used in order to optimize inspection conditions by analysing the effects of layer thicknesses, material properties, transducer type, frequency, bandwidth, etc. Specific signal processing techniques should probably be used for the very difficult problem of detecting bonding defects at the second interface in this type of structures.

\section{Acknowledgments}

This work has been supported by the Spanish R\&D Project CICYT Ref. DPI2005-00124, of the I+D National Plan (MEC).

\section{References}

[1] L.M. Brekhovskikh "Waves in layered media", Academic Press, New York (1980)

[2] B.A. Auld, "Acoustic fields and waves in solids", Second edition, Robert E. Krieger Publishing (1990)

[3] M.J.S. Lowe, "Matrix techniques for modeling ultrasonic waves in multilayered media", IEEE Trans. On Ultrasonics Ferroelectrics and Frequency Control, Vol. 44, No 4, pp. 525-542 (1995)

[4] X.M. Jian, N. Guo, M.X. Li, H.L: Zhang, "Characterization of bonding quality in a multilayer structure using segment adaptive filtering", Journal of Nondestructive Evaluation, Vol. 21, $\mathrm{N}^{\mathrm{o}} 2$, pp. 55-65 (2002)

[5] R. Kazys, L. Svilainis, "Ultrasonic detection and characterization of delaminations in thin composite plates using signal processing techniques", Ultrasonics, Vol. 35, pp. 367-383 (1997)

[6] C. Zhu, V.K. Kinra, "A new technique for time-domain ultrasonic NDE of extremely thin plates", Review of Progress in Quantitative Nondestructive Evaluation, Vol. 12, pp. 1099-1106 (1993)

[7] W.R. Scott, P.F. Gordon, "Ultrasonic spectrum analysis for non-destructive testing of layered composite materials", Journal of the Acoustical Society of America, Vol. 62, No 1, pp. 108-116 (1977)

[8] H. Sohn, G. Park, J.R. Wait, N.P. Limback, C.R. Farrar, "Wavelet-based active sensing for delamination detection in composite structures", Smart Materials and Structures, Vol. 13, pp. 153-160 (2004)
[9] A. Abbate, J. Koay, J. Frankel, S.C. Schroeder, P. Das, "Signal detection and noise suppression using a wavelet transform signal processor", IEEE Trans Ultrason Ferroelectr Freq Control, Vol. 44, pp. 14-25, (1997)

[10] J.C. Lazaro, J.L. San Emeterio, A. Ramos, J.L. Fernandez, "Influence of thresholding procedures in ultrasonic grain noise reduction using wavelets", Ultrasonics, Vol. 40, pp. 263-267, (2002)

[11] E. Pardo, J.L. San Emeterio, M.A. Rodriguez, A. Ramos, "Noise Reduction in Ultrasonic NDT using Undecimated Wavelet Transforms", Ultrasonics, Vol. 44, e1063-e1067 (2006)

[12] A.N. Sinclair, M. Jastrzebski, V. Safavi-Ardevili, "Ultrasonic evaluation of weak liner/Propellant bonding in a rocket motor", $16^{\text {th }}$ World Conference on NDT, Montreal (2004) 